public complaint. The consumer, he said, is entitled to demand that such industries avoid extravagant administration, attain a high degree of efficiency, pass to the consumer a substantial share of the results of higher productivity and have sufficient regard to the legitimate wishes of the consumer in matters of quality and variety.

Most of Mr. Morrison's address was devoted to an outline of the general organisation of the various public boards controlling certain industries in Britain, in which he stressed particularly the safeguards provided for the interest of the consumer. We have to rely on the various boards, Mr. Morrison said, to hold the balance fairly between consumer and worker, and he concluded that the consumer would be primarily dependent for a fair and reasonable level of price on the efficiency of the boards and their ability to keep both management and workers 'on their toes'. Such public boards should provide a reasonable safeguard against gross discrimination between consumers, but the address contained little evidence that the conditions Mr. Morrison specified are, in fact, being observed. It cannot now be seriously contended that even the Post Office passes on to the public the advantages in speed and efficiency which technical improvements have made possible, and the difficulties experienced in raising questions in the House of Commons regarding the public boards suggests that new means must be sought of making them sensitive to public opinion.

\section{Australian Council for Scientific and Industrial Research}

Desprte grave misrepresentation of its motives, the Executive Committee of the Australian Council for Scientific and Industrial Research appears to have convinced the Commonwealth Government that scientific work for war purposes should be conducted under the Ministry of Supply or the Ministry of Defence rather than under the Council. The contention is that the conditions of secrecy and military security essential nowadays for war-work will require an atmosphere in which the normal activities of the Council on behalf of primary and secondary industry simply cannot flourish. The Council has for twentytwo years operated under an Act, originated by Viscount Bruce, giving it a high degree of freedom and independence; for many reasons it is believed that, in existing conditions, the two contrasting lines of work cannot be effectively controlled by the one body.

In providing for the transfer to another Commonwealth agency, under public service board control, of the small amount of work bearing on defence at present conducted in the laboratories of the Council for Scientific and Industrial Research, a Bill now before Parliament unfortunately goes further and opens the way for subjecting any or all of the Council's activities to public service board procedure and regulations. Strong exception is being taken by scientific men and societies in Australia to this action, which is regarded as a serious threat to the spirit and successful working which have characterized the Council for Scientific and Industrial Research in the Fast.

\section{Australian Journal of Scientific Research}

A NEW periodical of high standard, the Australian Journal of Scientific Research, has recently been launched by the Australian Council of Scientific and Industrial Research, Melbourne, in collaboration with the Australian National Research Council (see Nature, August 7, 1948, p. 210). It is being issued quarterly in two series, Series A (Physical Sciences) and Series B (Biological Sciences), the price of each being $7 s .6 d$. The editor and chairman of the editorial board is Dr. N. S. Noble, and the other members of the board are Profs. W. J. Dakin, E. J. Hartung, L. H. Martin and J. G. Wood.

The first number (March 1948) of Series A contains seven papers on physical, chemical, metallurgical and meteorological subjects, indicating the variety of researches undertaken or sponsored by the Australian Council of Scientific and Industrial Research. These include: an analytical treatment, by G. H. Godfrey, of the distribution of light intensity in the Fraunhofer diffraction pattern of continuous light sources, in which attention is directed to certain diffraction effects which have not been previously recorded but which are in agreement with the theory; a study, by V. D. Hopper and A. M. Grant, of the effect of a horizontal wall on the motion of oil drops, of radii 5-15 $\mu$, falling in air, in order that the corrections to be applied in the precise determination of the electronic charge by the oil-drop method may be accurately made; observations on a strong variable source of radio frequency energy in the constellation of Cygnus ; a microscopic and X-ray examination of the deformation or recrystallization of a duplex brass; and the testing of molecular layers of the silicones on various metal surfaces for their boundary lubricating properties.

\section{German Scientific and Technical Periodicals}

THE Foreign Office of Great Britain has recently compiled a list of more than three hundred German scientific and technical periodicals which have resumed publication. The list is divided into the following sections : agriculture and forestry ; mathe. matics, physics and chemistry; medicine; natural science; and technology and industry. Very short notes, including the price where listed, are given with each periodical. Inquiries regarding the list should be made to the Foreign Office (German Section), Room 211, King Charles Street, London, S.W.1.

\section{Financial Aid for Delegates at Conferences}

THE British Council has a small fund for the assistance of overseas delegates wishing to attend national or international conferences held in the United Kingdom on scientific subjects including agriculture, engineering and medicine. Except in special circumstances, fares to and from the United Kingdom will not be paid, and the grants are mainly designed to cover subsistence of the delegate for the duration of the conference up to a period of two weeks. Conveners of conferences to be held during the period April 1, 1949-March 31, 1950, should apply to the Director, Visitors Department, British Council, 3 Hanover Street, London, W.1, giving full details including the number of delegates requiring assistance and their nationalities. Such information should be lodged preferably not later than January 15, and replies will be made by the end of February.

\section{World Federation for Mental Health}

THe World Federation for Mental Health, formed at the time of the international congress in London last August, has now been officially recognized for consultative purposes by the two United Nations 
bodies-the World Health Organisation and Unesco. The president of the World Federation, Dr. J. R. Rees (Great Britain), has expressed the hope that this consultative arrangement will lead to a further recognition of the importance of montal health in efforts to establish a healthier and happier world society. Dr. Rees also announced that the Federation has accepted the invitation of Unesco to send an observer to its general conference which opened at Beirut on November 17. The Federation is being represented by Dr. M. K. el Kholy, of Egypt, the member for the African Continent on the Executive Board.

The World Federation already comprises twentyone mental health associations of different nations, and others are expected to be admitted to membership in the near future. Dr. André Repond, of Switzerland, now vice-president, in accordance with the by-laws of the Federation, will succeed Dr. Rees as president next year. Prof. H. C. Rümke, of Holland, is chairman of the Executive Board, which will meet in Amsterdam in January. Arrangements are also now being made for the Assembly of the World Federation to be held in Geneva next August, when delegates from all over the world will be present.

\section{P. F. Frankland Memorial Lecture}

THE Birmingham and Midlands Section of the Royal Institute of Chemistry is endeavouring to collect $£ 1,500$ to establish a memorial lecture in honour of Percy Faraday Frankland, who occupied the Mason chair of chemistry in the University of Birmingham with great distinction during 1894-1918 and who died two years ago. The lectures will be delivered in Birmingham at intervals of three to four years and will deal mainly with original work; they will be published and may be expected to make a notable contribution to chemical literature. All money subscribed goes to the endowment; cheques drawn in favour of "P. F. Frankland Memorial Lecture", crossed a/c payee, should be sent to Mr. E. M. Joiner (secretary, Birmingham and Midlands Section, Royal Institute of Chemistry), 15 Halton Road, Sutton Coldfield, Warwickshire.

\section{Lantern Slides of Diagrams, Formulæ, etc.}

Is Nature of June 29, 1946, p. 879, and several earlier issues, correspondents described methods they had used successfully for writing on glass. Mr. E. H. Leach, University Laboratory of Physiology, Oxford, states that any ink to which a drop or two of a solution of a synthetic detergent ('Teepol' type) has been added can be used for writing on any clean glass surface. Indian ink appears to be the most suitable. Some proprietary brands of ink appear to contain synthetic detergent and require no further addition. Glassware and microscope slides can be marked with such inks.

\section{Hawaiian Libraries}

MANY people are unaware that excellent libraries exist in Hawaii in conjunction with that country's museums, university, research institutions and archives of the Government. For information on the holdings of these libraries a "Union List of Serials in Hawaii" is being prepared; the Committee on the Union List, Hawaii Library Association, Honolulu, Territory of Hawaii, invites pre-publication orders at 6 dollars a copy.

\section{Conference on Organised Information Services}

THE Northern Branch of Aslib has arranged a conference on the general theme of the value of organised information service to industry, commerce and education, to be held at the North of England Institute of Mining and Mechanical Engineers, Neville Hall, Westgate Road, Newcastle-upon-Tyne, on December 7. The chair will be taken by R. Trevor Jenkins, technical manager, Vickers-Armstrongs, Ltd., Elswick and Scotswood Works, Newcastleupon-Tyne. The conference will be opened at 10 a.m. by the Lord Mayor of Newcastle-upon-Tyne. Dr. V. E. Parke will speak on "Intelligence: Some Fundamental Principles", and will be followed by Mr. E. Austin Hinton on "Industrial, Technical and Commercial Information: The Contribution of the Public Library". In the afternoon session, at 2.30 p.m., Mr. R. O. MacKenna will speak on "Information Service from the point of view of the Universities", and will be followed by Mr. T. S. Nicol, who will deal with the point of view of professional associations. Miss J. Scurfield will speak on "The Regional Library Bureaux" ; Miss E. M. R. Ditmas will deal with the work of Aslib, and Mr. R. Brightman with that of the Northern Branch. Conference tickets can be obtained (5s. each) from the local organising secretary, Mr. M. G. Cahill-Byrne, Vickers-Armstrongs, Ltd., Elswick Works, Newcastle-upon-Tyne, 4.

\section{Comet 1948 I}

Dr. R. D'E. Atkinson, who led the Royal Observatory eclipse expedition, cabled confirmation of a bright comet seen in the southern sky early in November. During the eclipse on November 1 a photograph showed that the comet was $1^{\circ} 33^{\prime}$ from the centre of the sun, and it was then very bright with a tail. It has been seen in different parts of the southerm hemisphere since then. Its brightness has been estimated as mag. 2. Its daily motion is approximately $-8 \cdot 1 \mathrm{~m}$. in R.A. and $-51^{\prime}$ in declination. It is doubtful whether it will be seen from the British Isles. The latest description from the Cape Observatory states that the object is diffuse with central condensation or nucleus, and that the tail exceeds $1^{\circ}$ in length; hence some of the Press reports about the length of the tail were probably exaggerated.

The Royal Observatory, Cape Town, has communicated the following parabolic orbit and ephemeris computed by Hirst and Stoy :

$$
\text { Elements }
$$

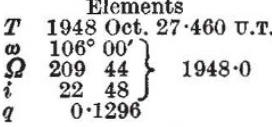

$$
\begin{aligned}
& \text { Ephemeris } \\
& \text { Oh. U.T. }
\end{aligned}
$$

\begin{tabular}{|c|c|c|}
\hline $\begin{array}{r}1948 \\
\text { Nov. } 14 \\
18 \\
22 \\
26\end{array}$ & 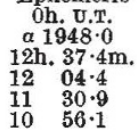 & $\begin{array}{r}\delta 1948 \cdot 0 \\
-25^{\circ} 53^{\prime} \\
2840 \\
3104 \\
3257\end{array}$ \\
\hline
\end{tabular}

\section{Announcements}

THE following higher degrees have been conferred by the University of Aberdeen: Ph.D., on G. F. Walker, for a thesis on "The Clay Mineralogy of some Aberdeenshire Soils" ; M.D., on H. MeL. Raffan, for a thesis on "Poliomyelitis in Aberdeenshire".

Erratum. Dr. Oscar Hechter states that the reference in the communication "Spreading Phenomenon and Inflammation" (Nature, October 30, p. 701) to earlier work (par. 4) should be to footnote 1, and not footnote 2 as appeared in his manuscript. 